\title{
A CASE OF INTRATONSILLAR ABSCESS MANAGED BY NEEDLE ASPIRATION
}

\author{
Jathin Sam Thekkethil1, Ciju Kunjumon George², Ravindrakumar Ningappa Karadi³, Isha Vidisha ${ }^{4}$
}

${ }_{1}^{1}$ Post Graduate, Department of Otorhinolaryngology and Head \& Neck Surgery, Shri B. M. Patil Medical College Hospital and Research Centre, Vijayapur.

2 Post Graduate, Department of Otorhinolaryngology and Head \& Neck Surgery, Shri B. M. Patil Medical College Hospital and Research Centre, Vijayapur.

3Professor \& HOD, Department of Otorhinolaryngology and Head \& Neck Surgery, Shri B. M. Patil Medical College Hospital and Research Centre, Vijayapur.

${ }^{4}$ Post Graduate, Department of Otorhinolaryngology and Head \& Neck Surgery, Shri B. M. Patil Medical College Hospital and Research Centre, Vijayapur.

\section{ABSTRACT}

Intratonsillar abscess is a rare complication of acute tonsillitis. It is a rarely diagnosed infection occurring in both children and adults. Herein, we present a case of intratonsillar abscess in a 25-year-old female patient, who was managed by needle aspiration which is a minimally invasive procedure and it is low cost, safe and effective along with antibiotic therapy. The aspiration of the pus from the tonsil confirms the diagnosis of intratonsillar abscess. So intratonsillar abscesses are uncommon, but should be considered in the differential diagnosis of peritonsillar abscess and tonsillitis.

\section{KEYWORDS}

Tonsil, Intratonsillar Abscess, Tonsillitis.

HOW TO CITE THIS ARTICLE: Thekkethil JS, George CK, Karadi RN, et al. A case of intratonsillar abscess managed by needle aspiration. J. Evolution Med. Dent. Sci. 2016;5(23):1265-1266, DOI: 10.14260/jemds/2016/295

\section{INTRODUCTION}

Intratonsillar abscess is a rare complication of acute tonsillitis. It is a rarely diagnosed infection occurring in both children and adults. The reported incidence of intratonsillar involvement is $5 \% .^{1}$ Herein, we present a case of intratonsillar abscess managed conservatively by needle aspiration.

\section{CASE REPORT}

A 25-year-old female presented to the outpatient department with history of pain during swallowing and fever of two days' duration. She gives a past history of recurrent tonsillitis during last 6 months, which subsided on taking medication. On examination, a localized swelling over the medial aspect of the right tonsil in the lower pole, which was yellowish and smooth with a cystic appearance and the surrounding tonsillar tissue was congested. The anterior pillar also showed congestion. Neck examination revealed tender cervical lymphadenopathy. She was managed conservatively with needle aspiration of pus from the abscess, which was sent for culture and sensitivity. She was put on broad-spectrum antibiotics, analgesics and antiseptic mouth gargle. She improved with the treatment and was symptom free on her next visit after 5 days. She was followed up for 3 months with no recurrence of abscess.

\section{DISCUSSION}

The palatine tonsils are situated at the lateral portions of the oropharynx. Each tonsil is bounded anteriorly and posteriorly by tonsillar pillars.

Financial or Other, Competing Interest: None.

Submission 06-02-2016, Peer Review 03-03-2016,

Acceptance 08-03-2016, Published 21-03-2016.

Corresponding Author:

Dr. Jathin Sam Thekkethil,

Post-Graduate,

Department of Otorhinolaryngology and Head \& Neck Surgery,

Shri B. M. Patil Medical College Hospital and Research Centre,

Vijayapur.

E-mail: jathinsam@gmail.com

DOI: $10.14260 /$ jemds/2016/295

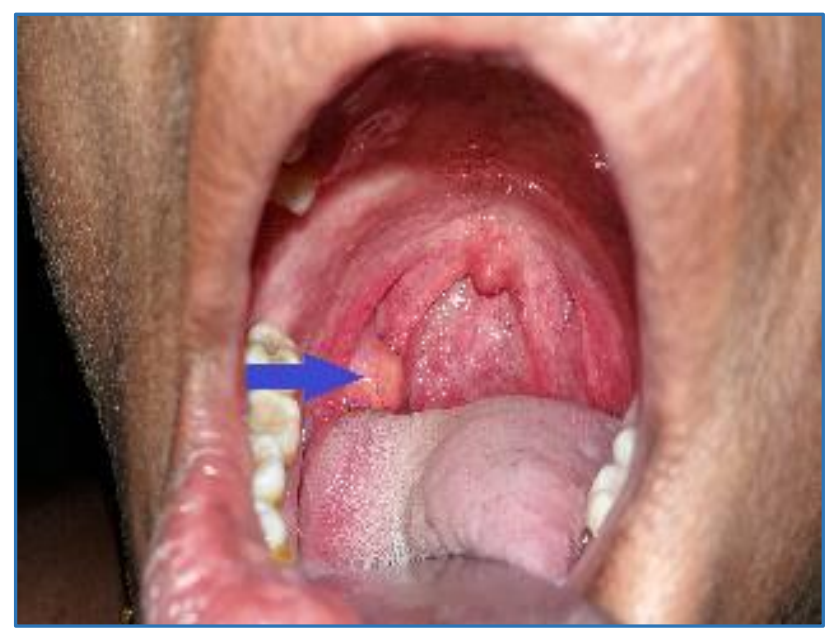

Fig. 1: Localized swelling over the medial aspect of the right tonsil, in the lower pole, yellowish and smooth with a cystic appearance and the surrounding tonsillar tissue was congested

The anterior pillar is formed by the palatoglossus muscle and posterior pillar is defined by the palatopharyngeus muscle. The medial surface of the tonsil is made up of multiple tonsillar crypts varying from 8-20 in number. The visible medial portion and the tonsillar crypts are covered by nonkeratinized squamous epithelium. The lateral surface (Base) is covered by a fibrous sheath. The palatopharyngeus muscle also gives rise to a muscle bundle named as the tonsillopharyngeus muscle, which is inserted into the fibrous septate of the tonsil and may function to compress it and to expel the content of the tonsillar crypts. ${ }^{2}$ Activation of the superior pharyngeal constrictors provides the stimuli for contraction of the tonsillopharyngeus. ${ }^{3}$ During an episode of acute follicular tonsillitis, a virulent organism gains entrance into the tonsillar crypts and begins to replicate in the base of the crypt. Localized oedema, influx of neutrophils and 
exfoliation of the crypt lining occur in response to bacterial proliferation. Failure to clear debris from within the crypts because of structural problems or local conditions may lead to inflammation and infection within the tonsil. ${ }^{4}$ Thus, parenchymal tonsillar abscesses may occur through two different mechanisms: direct extension of a crypt abscess into the tonsillar parenchyma or seeding of bacteria throughout the tonsil via the bloodstream or lymphatics.

The intratonsillar abscesses can be managed by needle aspiration, incision and drainage of the abscess, hot tonsillectomy or interval tonsillectomy. Needle aspiration of intratonsillar abscess as the primary treatment has proven to be low cost, less painful and a less invasive procedure which can be performed in the outpatient setting. ${ }^{5}$ Wang et al. performed needle aspiration on one of the three reported cases of unilateral intratonsillar abscesses; incision and drainage and conservative management on the other patients. ${ }^{5}$ So intratonsillar abscesses are uncommon, but should be considered in the differential diagnosis of peritonsillar abscess and tonsillitis.

\section{CONCLUSION}

Intratonsillar abscess is a rare complication of acute tonsillitis. The aspiration of the pus from the tonsil confirms the diagnosis of intratonsillar abscess. Needle aspiration of the abscess using a wide bore needle is a safe, minimally invasive and effective way of managing this condition.

\section{REFERENCES}

1. Childs EW, Baugh RF, Diaz JA. Tonsillar abscess. J Natl Med Assoc 1991;83:333-336.

2. Michaels L. The palatine tonsil-development; normal anatomy, histology; inflammatory diseases. In: Michaels L, Hellquist HB, editors. Ear, nose and throat histopathology. London: Springer-Verlag; 1987;1st edn:281-290.

3. Parkinson RH. Tonsil and allied problems. New York: MacMillan \& Co; 1951.

4. Sasaki CT, Koss N. Chronic bacterial tonsillitis: fact or fiction. Otolaryngology 1978;86:858-864.

5. Wang AS, Stater BJ, Kacker A. Intratonsillar abscess: 3 case reports and a review of the literature. Int J Pediatr Otorhinolaryngol 2013;77:605-607. 